\title{
Antiproliferative and Antimicrobial Effects of Tris(2-hydroxyethyl)ammonium-Based Protic Ionic Liquids with Some Fatty Acids
}

\author{
Hüseyin AKBAŞ ${ }^{1 *}$, Aslı YILDIRIM², Şeyma MENEVŞE², Nazan GÖKŞEN ${ }^{3}$
}

\begin{abstract}
Protic ionic liquids (PILs) that emerge as promising compounds are of great interest in industry and academia due to their easy synthesis and unique physical and chemical properties. This study aims to evaluate the antimicrobial activities against various microorganisms and the antiproliferative effects of four PILs namely, the PILs tris(2-hydroxyethyl)ammonium dodecanoate (TALA), tris(2-hydroxyethyl)ammonium tetradecanoate (TAMA), tris(2-hydroxyethyl)ammonium palmitate (TAPA) and tris(2-hydroxyethyl)ammonium stearate (TASA). Antiproliferative effects of PILs were investigated in vitro on breast cancer cell line (MDA-MB 231), colon cancer cell line (HT29) and prostate cancer cell line (PC3). Furthermore, minimum inhibitory concentrations (MIC) were established for PILs tested against rods, cocci and fungi. The antimicrobial activities of the PILs are strongly related to the alkyl chain length of the anion.
\end{abstract}

Keywords: Antibacterial effect, Antiproliferative effect, Protic ionic liquids

\footnotetext{
${ }^{1}$ Hüseyin AKBAŞ (Orcid ID: 0000-0002-3013-9033), Tokat Gaziosmanpaşa University, Science and Arts Faculty, Department of Chemistry, Tokat, Turkey

${ }^{2}$ Aslı YILDIRIM (Orcid ID: 0000-0001-5674-2095), Şeyma MENEVŞE (Orcid ID: 0000-0003-4005-6933), Tokat Gaziosmanpaşa University, Graduate School of Natural and Applied Science, Department of Bioengineering, Tokat, Turkey ${ }^{3}$ Nazan GÖKŞEN (Orcid ID: 0000-0001-5269-1067), Tokat Gaziosmanpaşa University, Graduate School of Natural and Applied Science, Department of Biomaterials and Tissue Engineering, Tokat, Turkey

*Sorumlu Yazar/Corresponding Author: Hüseyin AKBAŞ, e-mail: huseyin.akbas@gop.edu.tr
}

Geliş tarihi / Received: 26-02-2020 Kabul tarihi / Accepted: 12-05-2020 


\section{INTRODUCTION}

Ionic liquids (ILs) are defined as salts synthesized by combining organic cations with a wide variety of anions (Vekeriya, 2017; Akbaş, 2020). ILs also have many advantages physicochemical properties, such as low vapor pressure, high ionic conductivity, excellent thermal and chemical stability, a low melting point and favorable solvation properties (Tawfik, 2015). One of the most important features of ILs is their environmentally friendly and non-hazardous structures due to their negligible vapor pressures. ILs have gained great attention lately as green chemicals rather than traditional solvents (Earle and Seddon, 2000).

ILs are of great interest among the scientific community in the race to synthesize new pharmaceuticals, because of its various potential biological, pharmacological and pharmaceutical applications (Hough et al., 2007; Egorova et al., 2017; Egorova and Ananikov, 2018). In addition, ILs can be used as potential antimicrobial agents against gram-positive and gram-negative bacteria in the control of contamination and infection by potential microorganisms (Garcia et al., 2013). There are also studies on the anti-cancer activity of ILs against a panel of human cell lines, including melanoma, leukemia and cancers of the prostate, lung, breast and colon cell lines (Malhotra and Kumar, 2010; Rezki et al., 2018). Significant antiproliferative effects were also observed against five different human cancer cell lines with ILs based on ampicillin and thiabendazolium salts (Ferraz et al., 2015; El Bourakadi et al., 2019).

In this study, the PILs (TALA, TAMA, TAPA and TASA) were synthesized by using an equimolar amount of tris(2-hydroxyethyl)amine and long alkyl chain carboxylic acids (fatty acids). In addition to using classical chemotherapeutic in cancer treatment, new drug targets are being investigated and new molecules are trying to be defined in order to increase the effectiveness of the treatment. In vitro research on cell lines is of great importance in determining the effect of the agents used on cancer cells and using them as candidate molecules for cancer treatment. Antiproliferative effects of these PILs with long alkyl chains were investigated in vitro on MDA-MB-231, PC-3 and HT-29 which is one of the most commonly used breast cancer cell lines in medical researches. We have also applied experimental tests to determine their antimicrobial activity, towards two Gram-negative and one Gram-positive bacteria.

\section{MATERIALS AND METHODS}

Tris(2-hydroxyethyl) amine, lauric, myristic, palmitic and stearic acids were purchased from commercial sources (Sigma-Aldrich, St. Louis) and used without further purification.

All PILs were prepared as previously reported and analytical data were in accordance with the literature (Toledo Hijo et al., 2017). The PILs were synthesized from stoichiometric amounts of the tris(2-hydroxyethyl)amine as cation and the organic acids with different numbers of carbon atoms (lauric, myristic, palmitic and stearic acids) as anions. In order to eliminate traces of water either coming from the starting materials or from the atmosphere, the resulting mixtures were heated at $80{ }^{\circ} \mathrm{C}$ for $48 \mathrm{~h}$ under vacuum.

\section{Determination of Antiproliferative Effects of PILs}

Antiproliferative effects of PILs were investigated on MDA-MB-231, PC3 and HT29 cell lines using MTT (3-(4,5-dimethylthiazol-2-yl)-2,5-diphenyltetrazolium bromide) assay. This test was performed at eleven concentrations $\left(50-0.05\left(\mu \mathrm{g} \mathrm{mL}^{-1}\right)\right)$ and cells were left in contact with synthesized compounds for 24 and 48 hours. MDA-MB-231 cells were maintained in Dulbecco's Modified Eagle's Medium (DMEM, BiochromAg, Germany) which was supplemented with 10\% heat inactivated FBS and $1 \%$ l-glutamine, $100 \mathrm{IU} \mathrm{mL}^{-1}$ penicillin and $10 \mathrm{mg} \mathrm{mL}^{-1}$ streptomycin. Additionally, PC3 and HT29 
cells were cultivated with RPMI 1640 (BiochromAg, Germany) containing 10\% heat inactivated FBS. Cultured cells were grown in 96 well plates (Greiner Bio-One, Austria) and in a humidified atmosphere containing $5 \% \mathrm{CO}_{2}$ at $37{ }^{\circ} \mathrm{C}$. 5-Fu was used as a positive control reagent. A stock solution of the compounds was filter sterilized prior to addition to the culture plate. In each experimental set, cells were plated in triplicates and exposed to synthesized molecules at $37{ }^{\circ} \mathrm{C}$ in a humidified atmosphere of $5 \%$ $\mathrm{CO}_{2}$. After this incubation period, cells were incubated for three hours with an MTT solution $(0,5 \mathrm{mg}$ $\left.\mathrm{mL}^{-1}\right)$. Following the MTT removal after these incubation period, DMSO (100 mL) was added and complete dissolution of formazan crystals was achieved. After dissolution of purple formazan products, the optical density of the colored solution was measured at $570 \mathrm{~nm}$ using a microplate reader (Tecan, Switzerland). In order to determine the inhibitory effects of compounds, the cell viability of control has been accepted as $100 \%$, and the other results were proportioned according to the control value. Percentage of viable cells were calculated with the following formula: cell viability $\%=$ average absorbance of the treated group/ average absorbance of untreated group x 100 (İnan et al. 2018; İspir et al. 2019).

Differences in the mean values of measured activities were evaluated statistically using the SPSS 17.0 program (Univariate Variance Analyses and Pearson Correlation). Probability values of $\mathrm{p}<0.05$ were considered to be significant.

\section{Determination of Antimicrobial Properties of PILs}

The antimicrobial effects of PILs were examined with the aim of discovering new antimicrobial agents. In order to further explore the antimicrobial activity; we studied the minimal inhibitory concentrations (MIC) (Gökşen, 2016). The PILs of antibacterial activity was studied two gram-negatives (G-) bacteria and one gram-positive (G+) bacterium. Bacterial strains of Staphylococcus aureus (ATCC 25923 (G+)), Pseudomonas aeruginosa (ATCC 27853 (G-)), Klebsiella pneumonia (ATCC 15380 (G)) were used. Cultures were grown in exponential phase in nutrient broth at $37^{\circ} \mathrm{C}$ for $18 \mathrm{~h}$, adjusted to a final concentration of $10^{4} \mathrm{CFU} \mathrm{mL}^{-1}$ by diluting fresh broth medium. The MIC method was utilized for evaluating in vitro antimicrobial activity. The MIC is the lowest concentration of an antimicrobial agent that can inhibit the visible growth of a microorganism after overnight incubation. The study of solvent control indicated that $10 \%$ DMSO did not inhibit the growth of microorganisms. Also, in the present experiment, the concentration of DMSO was gradually decreased because of the two fold serial dilution assay (the working concentration was $5 \%$ and lower). So, the PILs synthesized for this study were solved in $10 \%$ DMSO and diluted from $50 \mathrm{mg} \mathrm{mL}^{-1}$ to $0.78 \mathrm{mg} \mathrm{mL}^{-1}$ in sterile 96 -well microtiter plates containing broth medium for bacteria. After dilution of samples, intensity of bacteria was standardized to equal a $0.5 \mathrm{McFarland}$ standard (approximately $5 \times 10^{7}$ organisms $\mathrm{mL}^{-1}$ ). The bacteria were then inoculated 96 well-plates and were incubated at $37{ }^{\circ} \mathrm{C}$ for $24 \mathrm{~h}$. After $24 \mathrm{~h}$, the optical density of each well was recorded at $600 \mathrm{~nm}$ using a microplate reader (Tecan, Switzerland). Each test included growth control and sterility control. The experiments were made three times, and the mean values were used.

\section{RESULT AND DISCUSSION}

\section{The Antiproliferative Properties of PILs}

Potential pharmaceutical applications of ILs were first demonstrated by studies on their toxicity and antimicrobial activity (Frizzo et al., 2013). The anticancer activity of ILs on breast cancer, prostate cancer and colon cancer cell lines has been studied. The effect on cell viability was observed depending on time and dose (Kumar and Malhotra, 2009) . 
As a result of MTT cell viability experiments, it was found that PILs did not significantly affect cell viability on MDA-MB 231 (Figure 1). Only TAMA and TALA were inhibited cancer cell viability weakly at low doses $(3.125 \mu \mathrm{M}$ and $1.5625 \mu \mathrm{M})$ at first 24 hours. On the second day, compounds have been shown to lose their antiproliverative effects. At the $48^{\text {th }}$ hour, TAPA compound was effective at low concentrations. Thus, it was determined that the antiproliferative effects of the tested compounds were much lower than the positive control group (5-Fu). On the other hand, they inhibited cancer cell proliferation weakly compared to the negative control (NC).
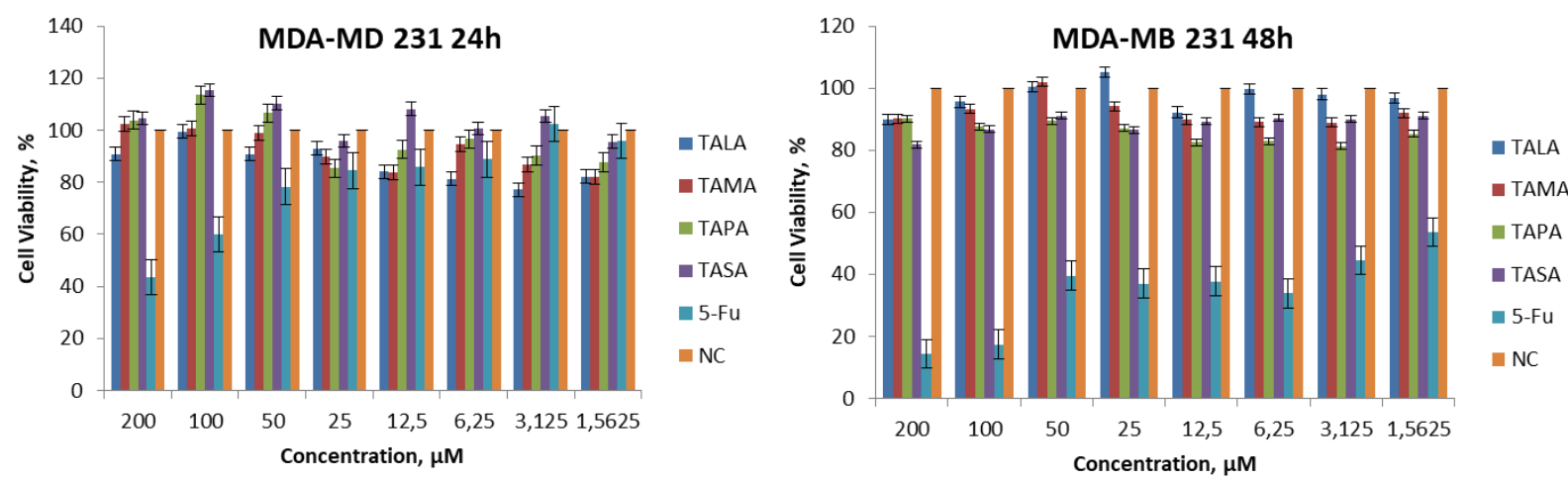

Figure 1. The effect of different concentration of PILs on the viability of MDA-MB 231 at 24 an 48 hours ( 5-Fu: 5- fluorouacil, NC: Negative control).

In the vitality analysis for HT-29 cell, it was seen that it has antiproliferative effect at the $24^{\text {th }}$ hour, but it was too weak, while it was observed that test compounds were increased cell viability at the $48^{\text {th }}$ hour. Based on these data, the differences between the groups were not significant (Figure 2).
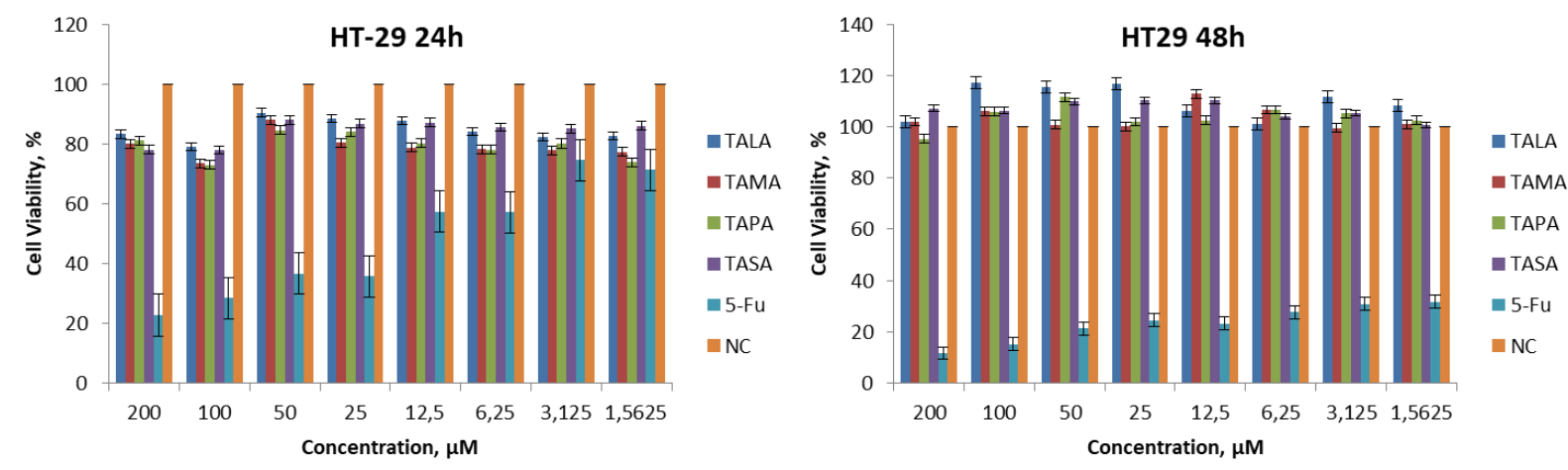

Figure 2. The effect of different concentration of PILs on the viability of HT-29 at 24 an 48 hours (5Fu: 5- fluorouacil, NC: Negative control).

In the MTT analysis for PC3 cell, there was an increase and decrease in cell viability at 24 hours. While the first three concentrations showed a weak antiproliferative effect, it was observed that this antiproliferative effect decreased when low doses were used. When compared with the negative control (NC) at $48^{\text {th }}$ hour, this situation varied considerably and it was seen that the antiproliferative effect of substances increases, and cell viability decreased up to $45 \%$ at $50 \mu \mathrm{M}$ (Figure 3). The most effective concentration of $50 \mu \mathrm{M}$ for these PILs in the PC3 cell was determined. It was determined that the antiproliferative effects of the tested compounds were much lower than the positive control group (5- 
$\mathrm{Fu}$ ). If ranking is made for the antiproliferative effects of the substances, it is interpreted as TASA, TAPA, TAMA and TALA.
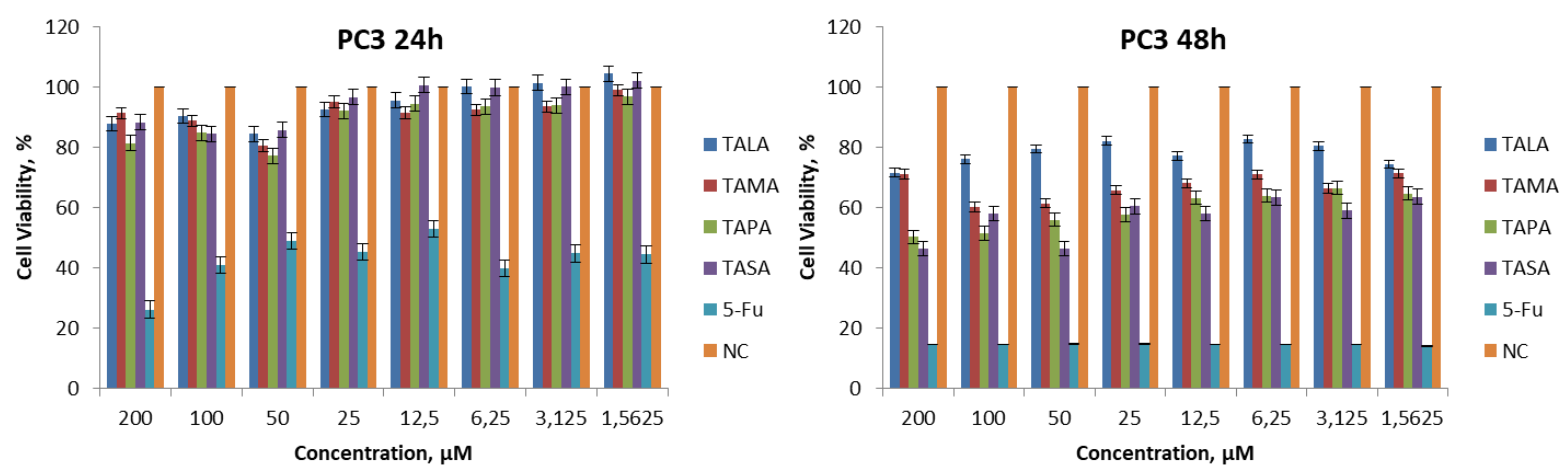

Figure 3. The effect of different concentration of PILs on the viability of PC-3 at 24 an 48 hours (5-

Fu: 5- fluorouacil, NC: Negative control).

\section{The Antimicrobial Activity of the PILs}

ILs are classically liquid at room temperature, but some of them are solid which can be dissolved in an appropriate solvent to form aqueous solutions. However, aqueous solutions of any ILs are no 'true' IL because they no longer consist exclusively of the parent ions, however such solutions retain potent antimicrobial activity (Freemantle, 2009). Anions play a subsidiary role in antimicrobial activity and the anions of antimicrobial effects can be negligible in most reported studies. As anions are known 'green solvent' (Pendleton and Gilmore, 2015), it is very important to discover and synthesize anions that will exhibit antimicrobial activity.

In the present study, the antimicrobial activity test was based on the MIC recommended by Gökşen (2016). The antibacterial effects of the PILs were examined with the aim of discovering new possible antimicrobial agents for use against some bacteria. One of the synthesized compounds were inhibited cell growths of both $\mathrm{G}(+)$ and $\mathrm{G}(-)$ bacteria. The compound coded TALA was exhibited antimicrobial activity on all of the bacterial strain. TAMA, TAPA and TASA compounds were no exhibited antimicrobial activity at used concentration range. The results of MIC showed in Table 1.

Table1. The determined MIC values $\left(\mathrm{mg} \mathrm{mL}^{-1}\right)$ of compounds ATCC bacterial strains.

\begin{tabular}{lccc}
\hline Compounds & S. aureus $($ ATCC 25923) & P. aeruginosa (ATCC 27853) & K. pneumonia (ATCC 15380) \\
\hline TALA & 50 & 50 & 50 \\
TAMA & - & - & - \\
TAPA & - & - & - \\
TASA & - & - & - \\
\hline
\end{tabular}

\section{CONCLUSION}

The biological activation of four PILs colon cancer, prostate cancer and breast cancer cell lines was investigated. These compounds appear to not significantly affect cell viability of colon and breast cancer cells. However, studies in prostate cancer cells show that its antiproliferative effect is quite good compared to the negative control.

Comparing the activity status of the substances in each cell line in these studied PILs, the results for MDA-MB 231 were found to be insignificant, and in this case there was no comparison of the efficacy status of any substances. For the HT-29 cell line, it can be listed as TAMA> TAPA> TASA> 
TALA. The activity order of the items at the $24^{\text {th }}$ and $48^{\text {th }}$ hours in the PC- 3 cell line changes. The chronic effectiveness of TASA, which has an acute efficacy compared to other substances, ranks first, with the opposite difference. When evaluated in general, it is seen that substances make more sense in chronic prostate cancer.

Without TALA compound, the PILs analyzed in the present study have no shown antimicrobial activity at used concentration range. The compound of TALA exhibited antimicrobial activity all of bacteria strain at a concentration of $50 \mathrm{mg} \mathrm{mL}^{-1}$.

\section{REFERENCES}

Akbaş H., 2020. Synthesis and spectroscopic characterization of protic tris (2-Hydroxyethyl)ammonium ionic liquids. JOTSCA, 7: 19-24.

Earle MJ and Seddon KR, 2000. Ionic liquids. Green solvents for the future. Pure Appl Chem, 72: 13911398.

Egorova KS and Ananikov VP, 2018. Fundamental importance of ionic interactions in the liquid phase: A review of recent studies of ionic liquids in biomedical and pharmaceutical applications. $\mathrm{J}$ Mol Liq, 272: 271-300

Egorova KS, Gordeev EG and Ananikov VP, 2017. Biological activity of ionic liquids and their application in pharmaceutics and medicine. Chem Rev, 117: 7132-7189.

El Bourakadi K, Merghoub N, Hicham G, El MehdiMekhzoum M, Essassi EM, Qaiss A and Bouhfid R, 2019. Synthesis, characterization and in vitro antiproliferative evaluation of ionic liquids based on alkyl-substituted thiabendazolium. J Mol Liq, 282: 63-69.

Erden Tayhan S, Bilgin S and Elmastaş M, 2018. Evaluation of the wound healing potential of Teucrioside. Int J Chem Tech, 2: 16-19.

Ferraz R, Costa-Rodrigues J, Fernandes MH, Santos MM, Marrucho IM, Rebelo LPN, Prudêncio C, Noronha JP, Petrovski Z and Branco LC, 2015. Antitumor activity of ionic liquids based on ampicillin. ChemMedChem., 10: 1480-1483.

Freemantle M, 2009. An introduction to ionic liquids. The Royal Society of Chemistry, Cambridge, UK.

Frizzo CP, Gindri IM, Tier AZ, Buriol L, Moreira DN and Martins MAP, 2013. Pharmaceutical salts: solids to liquids by using ionic liquid design. Ionic Liquids-New Aspects for the Future. IntechOpen.

Garcia MT, Ribosa I, Perez L, Manresa A and Comelles F, 2013. Aggregation behavior and antimicrobial activity of ester-functionalized imidazolium- and pyridinium-based ionic liquids in aqueous solution. Langmuir, 29: 2536-2545.

Gökşen N, 2016. Antimicrobial activities of essential oils of Mentha pulegium, Ziziphora tenuior and Echinophora tenuifolia and its effect on biofilm. Gaziosmanpaşa University Graduate School of Natural and Applied Sciences, Master Thesis (Printed).

Hough WL, Smiglak M, Rodri'guez H, Swatloski RP, Spear SK, Daly DT, Pernak J, Grisel JE, Carliss RD, Soutullo MD, Davis JH and Rogers RD, 2007. The third evolution of ionic liquids: active pharmaceutical ingredients. New J Chem, 31: 1429-1436.

İnan A, İkiz M, Erden Tayhan S, Bilgin S, Genç N, Sayın K, Ceyhan G, Köse M, Dağ A and İspir E, 2018. Antiproliferative, antioxidant, computational and electrochemical studies of new azocontaining Schiff base ruthenium complexes. New J Chem, 42: 2952-2963. 
İspir E, İkiz M, Inan A, Sünbül AB, Erden Tayhan S, Bilgin S, Köse M and Elmastaş M, 2019. Synthesis, structural characterization, electrochemical, photoluminescence, antiproliferative and antioxidant properties of $\mathrm{Co}(\mathrm{II}), \mathrm{Cu}(\mathrm{II})$ and $\mathrm{Zn}$ (II) complexes bearing the azo-azomethine ligands. $\mathrm{J}$ Mol Struct, 1182: 63-71.

Kumar V and Malhotra SV, 2009. Study on the potential anti-cancer activity of phosphonium and ammonium-based ionic liquids. Bioorg Med Chem Lett, 19: 4643-4646.

Malhotra SV and Kumar V, 2010. A profile of the in vitro anti-tumor activity of imidazolium-based ionic liquids. Bioorg Med Chem Lett, 20: 581-585.

Pendleton JN and Gilmore BF, 2015. The antimicrobial potential of ionic liquids: A source of chemical diversity for infection and biofilm control. Int J Antimicrob Agents, 46: 131-139.

Rezki N, Messali M, Al-Sodies SA, Naqvi A, Bardaweel SK, Al-blewi FF, Aouad MR and El Ashry ESH, 2018. Design, synthesis, in-silico and in-vitro evaluation of di-cationic pyridinium ionic liquids as potential anticancer scaffolds. J Mol Liq, 265: 428-441.

Tawfik SM, 2015. Simple one step synthesis of gemini cationic surfactant-based ionic liquids: Physicochemical, surface properties and biological activity. J Mol Liq, 209: 320-326.

Toledo Hijo AAC, Maximo GJ, Costa MC, Cunha RL, Pereira JFB, Kurnia KA, Batista EAC and Meirelles AJA, 2017. Phase behavior and physical properties of new biobased ionic liquid crystals. J Phys Chem B, 121: 3177-3189.

Vekeriya RL, 2017. A review of ionic liquids: Applications towards catalytic organic transformations. J Mol Liq, 227: 44-60. 